\section{References}

${ }^{1}$ Low-Beer TS, Pomare EW. Can colonic bacterial metabolites predispose to cholesterol gallstones? $\mathrm{Br} \mathrm{Med} \mathcal{F} 1975 ; \mathrm{i}: 438-40$

2 LaRusso NF, Szczepanik PA, Hofmann AF. Effect of deoxycholic acid ingestion on bile acid metabolism and biliary lipid secretion in normal subjects. Gastroenterology 1977;72:132-40.

${ }^{3}$ Ahlberg J, Angelin B, Einarrson K, Hellstrom K, Leijd B. Influence of deoxycholic acid on biliary lipids in man. Clinical Science and Molecular Medicine 1977;53:249-56.

${ }^{4}$ Carulli N, Ponz de Leon M, Zirori F, Iori R, Loria P. Bile acid feeding and hepatic sterol metabolism: effect of deoxycholic acid. Gastroenterology 1980;79:637-41.

5 Low-Beer TS, Nutter S. Colonic bacterial activity, biliary cholesterol saturation and pathogenesis of gallstones. Lancet 1978;ii:1063-5.

- Midtvedt T, Norman A. Parameters in $7 \alpha$-dehydroxylation of bile acids by anaerobic lactobacilli. Acta Pathol Microbiol Scand 1968;72:313-29.

${ }^{7}$ Aries V, Hill MJ. Degradation of steroids by intestinal bacteria II. Biochim Biophys Acta 1970;202:535-43.

${ }^{8}$ MacDonald IA, Singh G, Mahony DE, Meier CE. Effect of pH on bile salt degradation by mixed fecal cultures. Steroids $1978 ; 32: 245-56$.

- Bown RL, Gibson JA, Sladen GE, Hicks B, Dawson AM. Effects of lactulose and other laxatives on ileal and colonic $\mathrm{pH}$ as measured by a radiotelemetry device. Gut $1974 ; 15: 999-1004$.

10 Vlahcevic ZR, Bell CC, Juttijudata P, Swell L. Bile-rich duodenal fluid as an indicator of biliary lipid composition and its applicability to detection of lithogenic bile. Am $\mathcal{F}$ Dig Dis $1971 ; 16: 797-802$.
${ }^{11}$ Bolton CH, Low-Beer TS, Pomare EW, Wicks ACB, Yeates J, Heaton KW. A simplified procedure for the analysis of cholesterol, phospholipids and bile salts in human bile. Clin Chim Acta 1978;83:177-81.

12 Hegardt FG, Dam H. The solubility of cholesterol in aqueous solutions of bile salts and lecithin. $Z$ Ernachrungswiss 1971;10:223-33.

13 Andersen JM. Chenodeoxycholic acid desaturates bile-but how? Gastroenterology 1979;77:1146-51.

${ }^{14}$ Pomare EW, Low-Beer TS. The selective inhibition of chenodeoxycholate synthesis by cholate metabolites in man. Clinical Science and Molecular Medicine 1975; 48:315-21.

${ }^{15}$ Igimi H, Carey MC. pH-solubility relations of chenodeoxycholic and ursodeoxycholic acids: physical-chemical basis for dissimilar solution and membrane phenomena. 7 Lipid Res 1980;21:72-90.

${ }^{16}$ Eastwood MA, Hamilton D. Studies on the adsorption of bile salts to nonabsorbed components of diet. Biochim Biophys Acta 1968;152:165-73.

17 Pomare EW, Heton KW, Low-Beer TS, Espiner HJ. The effect of whea bran upon bile salt metabolism and upon the lipid composition of bile in gallstone patients. Am $\mathcal{F}$ Dig Dis 1976;21:521-6.

18 Cummings JH, Hill MJ, Jenkins DJA, Pearson JR, Wiggins HS. Changes in fecal composition and colonic function due to cereal fiber. Am $\mathcal{F}$ Clin Nutr 1976;29:1468-73.

19 Dowling RH. Chenodeoxycholic acid therapy of gallstones. In: Paumgartner $\mathrm{G}$, ed. Clinics in gastroenterology. Bile acids. London: W B Saunders Ltd, 1977:141-63.

(Accepted 15 Fanuary 1981)

\title{
Diagnosis of deep vein thrombosis using autologous indium-III-labelled platelets
}

\author{
ALBERT FENECH, J K HUSSEY, F W SMITH, P P DENDY, B BENNETT, A S DOUGLAS
}

\begin{abstract}
Forty-eight patients who had undergone surgical reduction of a fractured neck of femur or in whom deep vein thrombosis was suspected clinically were studied by ascending phlebography and imaging after injection of autologous indium-111-labelled platelets to assess the accuracy and value of the radioisotopic technique in diagnosing deep vein thrombosis. Imaging was performed with a wide-field gammacamera linked with data display facilities. Phlebography showed thrombi in 26 out of 54 limbs examined and a thrombus in the inferior vena cava of one patient; imaging the labelled platelets showed the thrombi in 24 of the 26 limbs and the thrombus in the inferior vena cava.

The accumulation of indium-111 at sites corresponding to those at which venous thrombi have been shown phlebographically indicates that this radioisotopic technique is a useful addition to methods already available for the detection of deep vein thrombosis.
\end{abstract}

University of Aberdeen, Foresterhill, Aberdeen AB9 2ZD ALBERT FENECH, MD, MRCP, lecturer in medicine

J K HUSSEY, MB, DMRD, senior registrar, department of radiology F W SMITH, MB, FFR, consultant, department of nuclear medicine $P$ P DENDY, PHD, reader, department of biomedical physics and bioengineering

B BENNETT, MRCP, MRCPATH, senior lecturer in medicine

A S DOUGLAS, FRCP, FRCPATH, regius professor of medicine

\section{Introduction}

The diagnosis of deep vein thrombosis on the basis of clinical signs is difficult and frequently incorrect, ${ }^{1-3}$ with the exception of phlegmasia dolens, when the clinical features are reliable indicators. ${ }^{4}$ Most deep vein thrombi, however, are less extensive and thus present fewer clear-cut clinical features than phlegmasia, though they still carry the risk of major pulmonary embolism. This risk necessitates objective confirmation of a clinical suspicion of deep vein thrombosis, and various methods have been used for this including ascending phlebography, detection of Doppler flow, impedance plethysmography, thermography, and radioisotopic techniques ( ${ }^{125}$ I-fibrinogen, ${ }^{123} \mathrm{I}$-fibrinogen, ${ }^{99 \mathrm{~m}} \mathrm{Tc}$-macroaggregated albumin, ${ }^{99 \mathrm{~m}} \mathrm{Tc}$ urokinase, and ${ }^{99 \mathrm{~m}} \mathrm{Tc}$-plasminogen). Unfortunately, all these methods have drawbacks limiting their use. ${ }^{4}$ An ideal diagnostic technique must be painless; non-invasive; safe and free from side effects; simple and reliable; rapid; accurate in detecting the site, size, and number of thrombi, whether recent or old; repeatable; financially acceptable; and require minimal transportation of the patient. No method currently satisfies these criteria, and new methods require to be established and examined.

We describe a simple, rapid technique for labelling autologous human platelets with indium-111 and imaging with a gammacamera to detect deep vein thrombosis and compare the accuracy of this method with that of ascending phlebography.

\section{Materials, methods, and patients}

Autologous platelets were labelled by using the technique developed by Hawker et al. ${ }^{6}$ This entailed removing $26 \mathrm{ml}$ of blood and separating the platelets, which were labelled with $180-220 \mu \mathrm{Ci}$ of indium-111 oxine (Radiochemical Centre) and reinjected within 45 minutes of 
removal from the patient. Imaging was performed within 24 hours of injection of the labelled platelets using a wide-field gammacamera (Ohio Nuclear) fitted with a medium-energy collimator. The camera was linked to a gamma 11 computer with data display facilities. Imaging was performed in three views-namely, anterior pelvic, showing the inferior vena cava and iliac veins; anterior thigh, showing vessels from the groin to the knee; and anterior calf, extending from the knee to the ankle. Each view was imaged for five minutes, and the imaging procedure was completed within 20 minutes.

The phlebographic method used was an adaptation of the standard double-cuff technique. The examination was performed on a tilting screening table using a GEC Kompact 9/5 image intensifier with a Summit 1253 generator. A blood-pressure cuff was placed round the lower thigh and a tourniquet applied round the ankle. Using a 21-gauge butterfly cannula inserted in a suitable vein on the dorsum of the foot, $50 \mathrm{ml}$ of Urografin $310 \mathrm{M}$ was injected during screening. When full opacification was achieved in the calf the above-the-knee cuff was inflated to just below systolic pressure. Three films of the calf were taken, and these included the popliteal vein. The patient was then tilted $20^{\circ}$ feet down and the above-knee cuff released, thus permitting controlled filling of the deep venous system above the knee. This was screened throughout and films taken of the thigh and pelvic veins. Results of the indium-111-labelled platelet imaging and the phlebograms were reported independently by two observers (FWS and JKH).

We studied 48 patients. Thirty-three had undergone surgical reduction of a fractured neck of femur and were studied routinely postoperatively. The 15 others had been admitted to hospital because of a clinical suspicion of deep vein thrombosis. Informed consent was obtained, and the hospital ethical committee approved the study. We had initially intended to perform platelet labelling with imaging and bilateral ascending phlebography on each patient. Platelet labelling with imaging was carried out in all patients but bilateral phlebography did not prove possible in all cases as some patients declined to undergo phlebography a second time because they had found the procedure uncomfortable. Thus in the patients with a presumptive clinical diagnosis of deep vein thrombosis the initial phlebogram was of the leg under suspicion and in the patients with a fracture it was of the fractured limb; phlebography was performed on the opposite limb whenever possible. Ascending phlebography was carried out within 48 hours of imaging except in one patient, who was considered to have become too unwell to be moved immediately before the planned phlebography; in this patient phlebography was delayed for one week. In two patients ascending phlebograms failed to define the iliofemoral segment adequately and femoral phlebography was performed to achieve this. Two patients were excluded from the final analysis because of incomplete phlebographic study.

\section{Results}

Phlebograms were obtained of 54 limbs in 46 patients and disclosed thrombi in 26 limbs and a thrombus in the inferior vena cava in one patient. The number and site of the thrombi were: inferior vena cava one, iliofemoral 12 , femoral 11 , popliteal two, calf 12 , and other three. Indium-111 imaging showed accumulations of the label in 24 of the 26 limbs positive on phlebography and in the inferior vena cava of the patient with the phlebographically proved thrombus; the location, number, and extent of these accumulations ("hot spots") correlated closely with the site at which thrombi were disclosed phlebographically. No false-positive results were observed (sensitivity $95 \%$, specificity $100 \%$ ). Figures 1 and 2 show the indium-111-labelled platelet image and the corresponding phlebogram obtained in one of the patients. Figures 3-5 illustrate thrombi demonstrated in other sites. Two patients with phlebographically shown deep vein thrombosis (one in the calf and one in the iliofemoral vein) did not show accumulation of the label at these sites but were taking regular doses of paracetamol and dextropropoxyphene, which may have influenced platelet adhesion to the thrombi. ${ }^{7}$ Eight patients in the group suspected clinically of having a deep vein thrombosis were receiving heparin by infusion, and four were taking oral anticoagulants at the time of the study; as reported by other workers these drugs did not appear to affect platelet deposition on the thrombi. ${ }^{8} 9$ The oldest thrombus detected in this series was five weeks old as judged on clinical grounds but still accumulated sufficient label to produce a hot spot detectable on imaging.

Accumulation of the label appeared to occur along the entire length of the thrombi, but in general the proximal end of long thrombi appeared to concentrate the label to a greater degree than the peripheral end. Two patients had thrombi that on phlebography were shown to occlude the affected veins totally (one in the femoral and one in the common iliac vein). The presence of these thrombi was detected by the indium-111 method owing to appreciable accumulation of label on their proximal ends; thus their presence but not their extent was shown by the technique. The extent of occlusive thrombi may be determined as follows: by greatly increasing the sensitivity of the display the major vascular columns of blood in the thighs and pelvis are demonstrated owing to the presence of circulating labelled platelets. Should a segment of vein be totally occluded by thrombus it will be demonstrated by this manoeuvre. Such a deficit in the images was seen in these two patients.

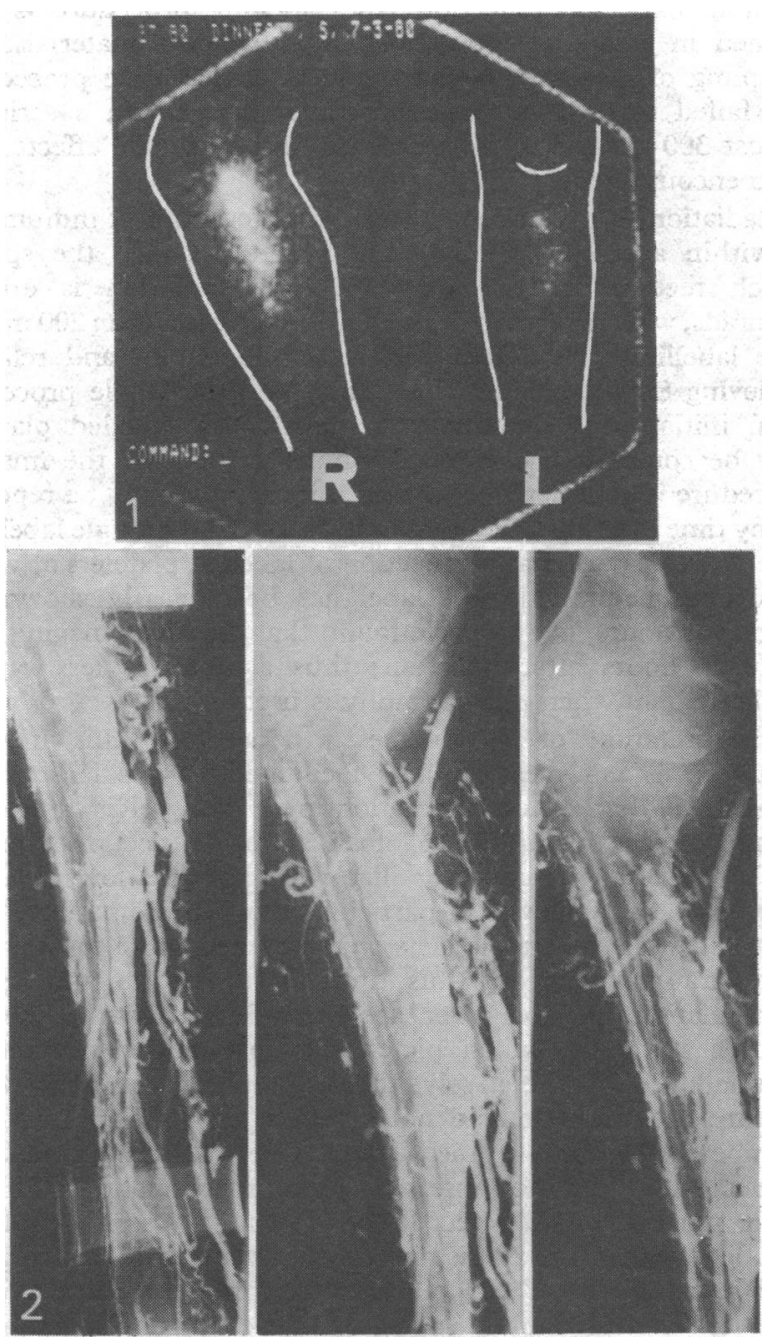

FIG 1-Anterior image of calves, showing large hot spot in right calf and smaller one in left. FIG 2-Phlebogram of right calf (same leg as in figure 1), showing extensive thrombus in calf veins.
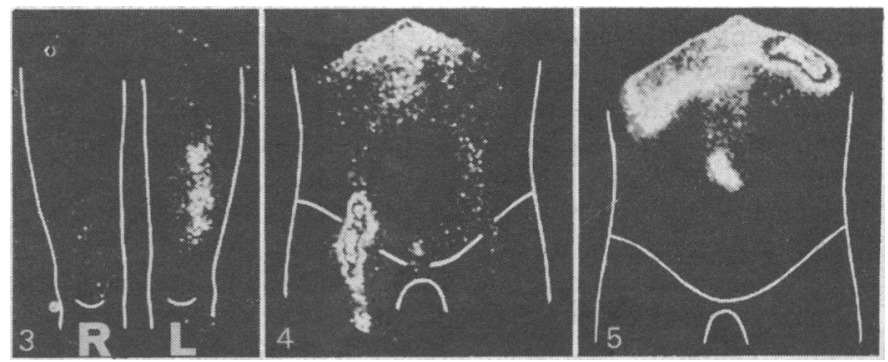

FIG 3-Anterior image of thighs, showing hot spot in left thigh corresponding to thrombus in this region. FIG 4-Anterior pelvic image, showing right ileofemoral hot spot corresponding to thrombus in this region. FIG 5Anterior pelvic image, showing hot spot over inferior vena cava extending to left ilial vein. 


\section{Discussion}

As we reported earlier, ${ }^{10}$ the indium-labelled platelet technique is capable of detecting venous thrombosis. This study has shown accumulation of indium-111, and, by assumption, of the platelets carrying the label, at sites corresponding to those at which venous thrombi have been shown phlebographically with sufficient consistency (24 out of 26 cases) to indicate that the technique is a useful addition to those available for the detection of deep vein thrombosis. The procedure is painless, which is a considerable advantage as discomfort is sometimes associated with ascending phlebography. In our hands it is safe and free from side effects. The most obvious possible hazard is infection; the labelling procedure is performed in a laminar flow cabinet with sterile materials, and sampling of labelled platelets from 50 consecutive procedures has failed to disclose bacterial contamination. In a series of almost $\mathbf{3 0 0}$ labelling procedures no untoward side effects have been encountered.

Radiation to the patient using the stated dose of indium-111 is within acceptable limits. The target organ is the spleen, which receives 5-6 rads; whole-body radiation is around 70 mrads, whereas that to the genital region is less than 200 mrads. The labelling procedure itself is simple, rapid, and reliable, achieving $80 \%$ labelling consistently and the whole procedure from initial venepuncture to reinjection of labelled platelets may be completed within 45 minutes. Similarly, the imaging procedure is completed within 20 minutes and may be repeated at any time over a period of up to five days after a single labelling. The shortest period after injection of labelled platelets at which abnormal accumulation of label has been clearly shown has been four hours, but we have found that the ideal imaging time is 20-24 hours after injection; thus a result is less rapidly available than when phlebography is used.

Interpretation of the images produced by this imaging technique is fairly easy and is facilitated by the lack of any appreciable background radiation over the pelvis and legs, permitting the identification of an abnormal accumulation of label in the calf, femoral, or iliac veins and the lower part of the vena cava. This was of particular value in the patients with fractured hips. Their platelets were labelled three to five days postoperatively, and by this time there was no appreciable accumulation of label over the wound or fracture site. In another study, in which platelets of patients with fractures were labelled preoperatively, the accumulation of label at the fracture/operation site did not interfere with interpretation as it appeared lateral to the venous tree. Varicose veins and venous stasis did not interfere with interpretation. Thus a single procedure will detect lesions in the calves and thighs in both legs and in the pelvis and inferior vena cava, and appears to detect both fresh and old thrombi; in these respects it is superior to the method using ${ }^{125}$ I-labelled fibrinogen. The technique requires that the patient be transported for imaging as is the case with most other isotopic techniques and phlebography. In this respect it is less convenient than the ${ }^{125} \mathrm{I}$-labelled fibrinogen method, which does not require patient transportation. With the advent of mobile gammacameras, however, this will cease to be a problem in the future. The cost of indium per patient will vary according to the number of patients labelled from $1 \mathrm{mCi}$ of indium oxine ( $1 \mathrm{mCi}$ costs $£ 35$ ).

Apart from the diagnostic advantages conferred our observations are interesting in respect of the dynamics of thrombus development. They suggest that platelets are absorbed on to the surface of relatively old thrombi in appreciable numbers, while the observations made with the labelled fibrinogen method suggest that fibrinogen is not similarly laid down in appreciable quantities in old venous thrombi.

The technique described uses a radioisotope linked to a physiological carrier (the platelet) that appears to have affinity for thrombi with characteristics that confer advantages over fibrinogen. Additionally, the technique detects proximal thrombi in the thighs, iliac veins, and the vena cava, which represents an additional advantage over the ${ }^{125}$ I-labelled $\underline{\underline{T}}$ fibrinogen method. The technique detects thrombi with considerable accuracy as compared with the standard procedure of ascending phlebography and warrants consideration as a useful addition to the methods available for the detection of deep vein thrombosis.

We thank Joyce Davidson and Lesley Kemp for their excellent technical help, and the orthopaedic surgeons of the Royal Infirmary for allowing us to study their patients.

\section{References}

${ }^{1}$ McLachlin J, Richards T, Paterson JL. An evaluation of clinical signs in the diagnosis of venous thrombosis. Arch Surg 1962;85:738-44.

2 Haeger K. Problems of acute deep venous thrombosis. I. The interpretation of signs and symptoms. Angiology 1969;20:219-22.

${ }^{3}$ Gallus AS, Hirsh J, Hull R, et al. Diagnosis of venous thromboembolism. Semin Thromb Haemostas 1976;2:203-25.

${ }^{4}$ Hull R, Hirsh J. Diagnosis of venous thrombosis by invasive and noninvasive techniques. In: Joist JH, Sherman LA, eds. Venous and arterial thrombosis. New York: Grune and Stratton, 1979:33-56.

${ }^{5}$ Browse NL. Diagnosis of deep vein thrombosis. Br Med Bull 1978;34: 163-7.

${ }^{6}$ Hawker RJ, Hawker LM, Wilkinson AR. Indium ('11 In)-labelled human platelets: optimal method. Clin Sci Mol Med 1980;58:243-8.

O'Brien JR Effect of anti-inflammatory agents on platelets. Lancet $1968 ; \mathrm{i}: 894-5$.

${ }^{8}$ Davis HH, Heaton WA, Siegel BA, et al. Scintigraphic detection of atherosclerotic lesions and venous thrombi in man by indium-111 labelled autologous platelets. Lancet $1978 ; \mathrm{i}: 1185-7$.

' Goodwin DA, Bushberg JT, Doherty PW, Lipton MJ, et al. Indium-111labelled autologous platelets for location of vascular thrombi in humans. f Nucl Med 1978;19:626-34.

${ }^{10}$ Fenech A, Dendy PP, Hussey JK, Bennett B, Douglas AS. Indium-111 labelled platelets in diagnosis of leg vein thrombosis: preliminary findings. $\mathrm{Br} \mathrm{Med} \mathcal{F} 1980 ; 280: 1571-3$.

(Accepted 28 fanuary 1981)

ONE HUNDRED YEARS AGO There can be no doubt that the town of Hastings is likely to suffer considerably, when the knowledge is spread among the medical profession that the important appointment of medical officer of health has been filled in a manner of which the profession in the town wholly disapprove. A town such as Hastings offers many advantages to visitors for health-purposes; but it is also replete with dangers. Only last week, we had a serious complaint addressed to us of the want of sanitary precautions in one of the lodging-houses, in respect to the arrival of an imperfectly convalesced scarlatina patient, and want of adequate enforcement of quarantine arrangements. Hastings has enjoyed the reputation, under the charge of Mr Ashenden, with the vigorous assistance of Mrs Johnston, of having organised a system by which epidemic and zymotic disease could be kept in check, and was provided with unusual sanitary safeguards for visitors. The carrying out of such a system, most essentially in a town of lodging-houses, which aims at becoming a health-resort, depends for its success very largely upon the complete, hearty, and intimate co-operation of the medical men generally with the medical officer of health, and on the delicate relations which must constantly arise in carrying out such a system. The spontaneous aid, information, and concurrence afforded by the private practitioner constitute primary elements of success in the sanitary regulation of a seaside resort, and the consequent readiness of the medical profession to recommend their clients to resort to it.-In relation to the above, the following memorial is being influentially and numerously signed for presentation, to the Mayor of Hastings.

We, the undersigned inhabitants of the borough, do respectfully ask you to convene, at your earliest convenience, a public meeting, to protest emphatically against the late appointment of the medical officer of health against the general wish of the inhabitants, which we consider calculated to do infinite damage to the trade and prosperity of the town, by bringing disrepute upon it as a health-resort, which is assuredly evinced by strictures passed in the leading medical journals, and is thus brought under the notice of the profession, who will assuredly refrain from recommending their patients to come here if such appointment be maintained. (British Medical fournal, 1881.) 